\title{
Raiseboring in difficult rock conditions
}

\author{
C Edelbro Itasca Consultants $A B$, Sweden \\ R Brummer Itasca Consulting Canada Inc., Canada \\ M Pierce Pierce Engineering, USA \\ D Sandström Boliden Mineral AB, Sweden \\ J Sjöberg Itasca Consultants $A B$, Sweden
}

\begin{abstract}
Virtually all long ventilation shafts and orepasses in the Boliden mines in Sweden are excavated using raiseboring. With increasing mining depths and hence, increased virgin rock stresses, it has become difficult to keep the shafts intact after boring and until reinforcement or other stabilising measures have been implemented.

This paper contains a review of literature and case studies of raiseboring in difficult rock conditions. The focus is on design, pre-reinforcement, excavation methods, and final outcomes. The cases range from long ventilation raises to short stope slots. The data was used to further develop raisebore design charts relating to the ratio of maximum tangential stress and uniaxial compressive strength (UCS) to raisebore length and diameter. This enabled establishing limits for initiation of failure and problem-free boring that can be achieved using current technology.

For problematic shafts, remedial measures such as different types of pre-reinforcement or lining the raise while pulling out the muck are presented. Good experiences using rings of reinforced piles to allow raiseboring through the deep weathered surface were available from Australia. However, there were no case studies with pre-reinforcement in rock conditions similar to those of the Boliden mines. Nevertheless, vertically drilled and pre-reinforced perimeter holes around the eventual raisebore diameter is one suggested possible action. Based on industry experience, strategies to be considered for raiseboring in difficult rock condition are also presented.
\end{abstract}

Keywords: raise, shaft, pre-reinforcement

\section{Introduction}

Virtually all long ventilation shafts and orepasses in the Boliden mines are excavated using raiseboring. Shaft dimensions vary from 25 to $650 \mathrm{~m}$ in length and with diameters between 2.0 and $6.5 \mathrm{~m}$. With increasing mining depths and hence, increased virgin rock stresses, it has become difficult to keep the shafts intact after boring, and until reinforcement or other stabilising measures have been implemented. Typical problems during reaming and pilot drilling include:

- Convergence in the pilot hole or in the shaft (Figure 1).

- Stability problems at the face and/or in the wall.

- Stability problems in nearby drifts.

- Hard rock - uneven load on the reaming head. 


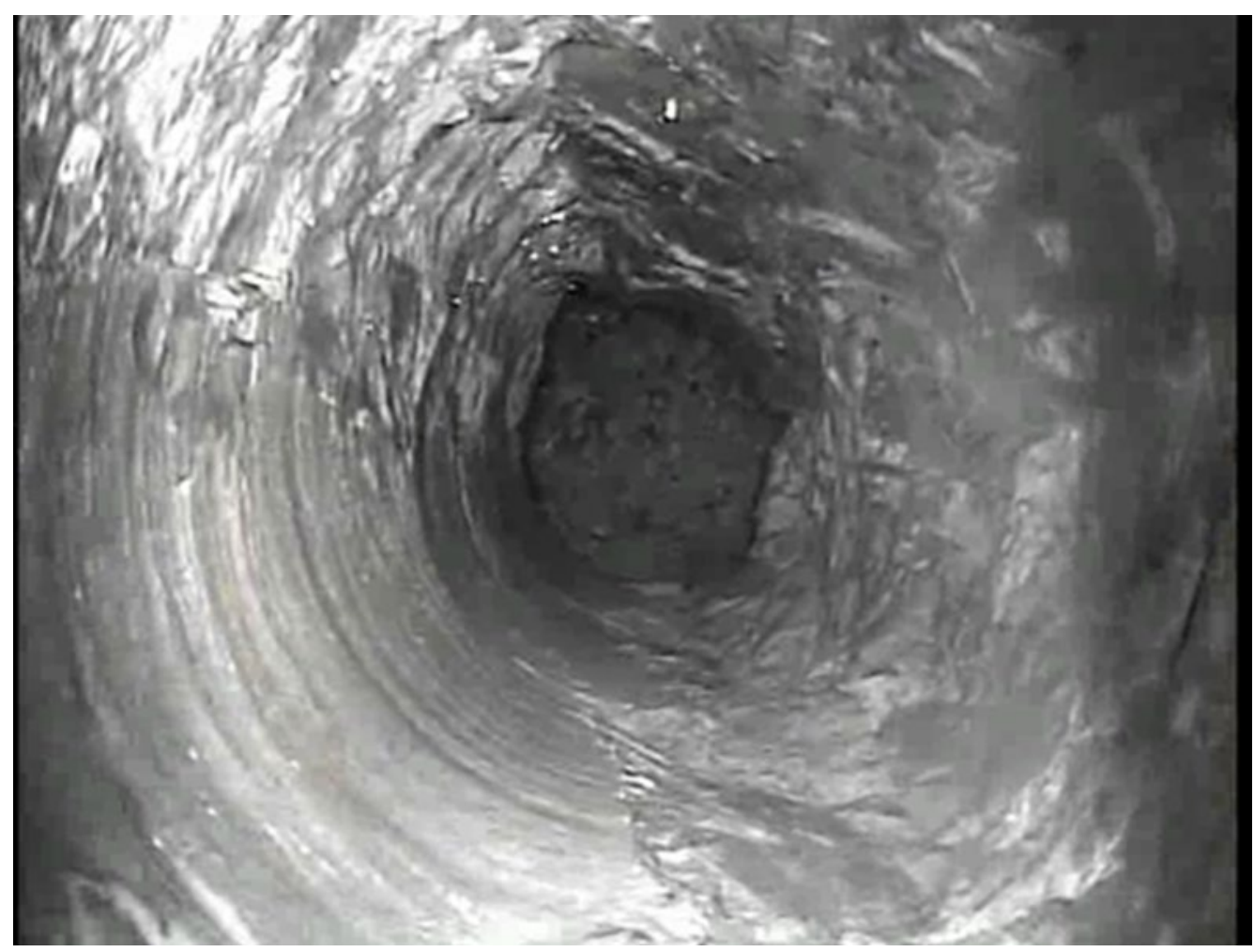

Figure 1 Stability problem after reaming, with difficulty to take down the reaming head and change cutters due to large convergence

This paper comprises a review of literature and case studies of raiseboring in difficult rock conditions, focusing on design approaches, pre-reinforcement, excavation methods, and final outcomes. Moreover, remedial measures to reduce the potential for instability during raiseboring were evaluated based on the literature review and gained experiences.

\section{$2 \quad$ Methodology and data sources}

A comprehensive literature review has been conducted using internet searches in Google, online literature databases (Scopus, Web of Science, Google Scholar etc.) and publications available at Swedish universities. Industry experience with developing raisebores in difficult ground has been summarised. Input from 13 international clients was solicited and the data and, in particular, the experience on managing raiseboring in ground that is overstressed, heavily jointed, or very weak and schistose, was consolidated. The majority of the industry clients operate deep mines, and this is reflected in the collected data. Clients were provided with an introductory letter and a set of blank data sheets (Figure 2). Replies were received from seven client organisations, and over 60 completed data sheets were returned. Not all of the completed data sheets included the required stress and rock strength data, and many of the raisebores described were completed without problems. The data obtained from clients was supplemented with data based on personal experience as well as similar previous projects. 
Itasca/Boliden Raisebore Project

Case History Summary Data Sheet

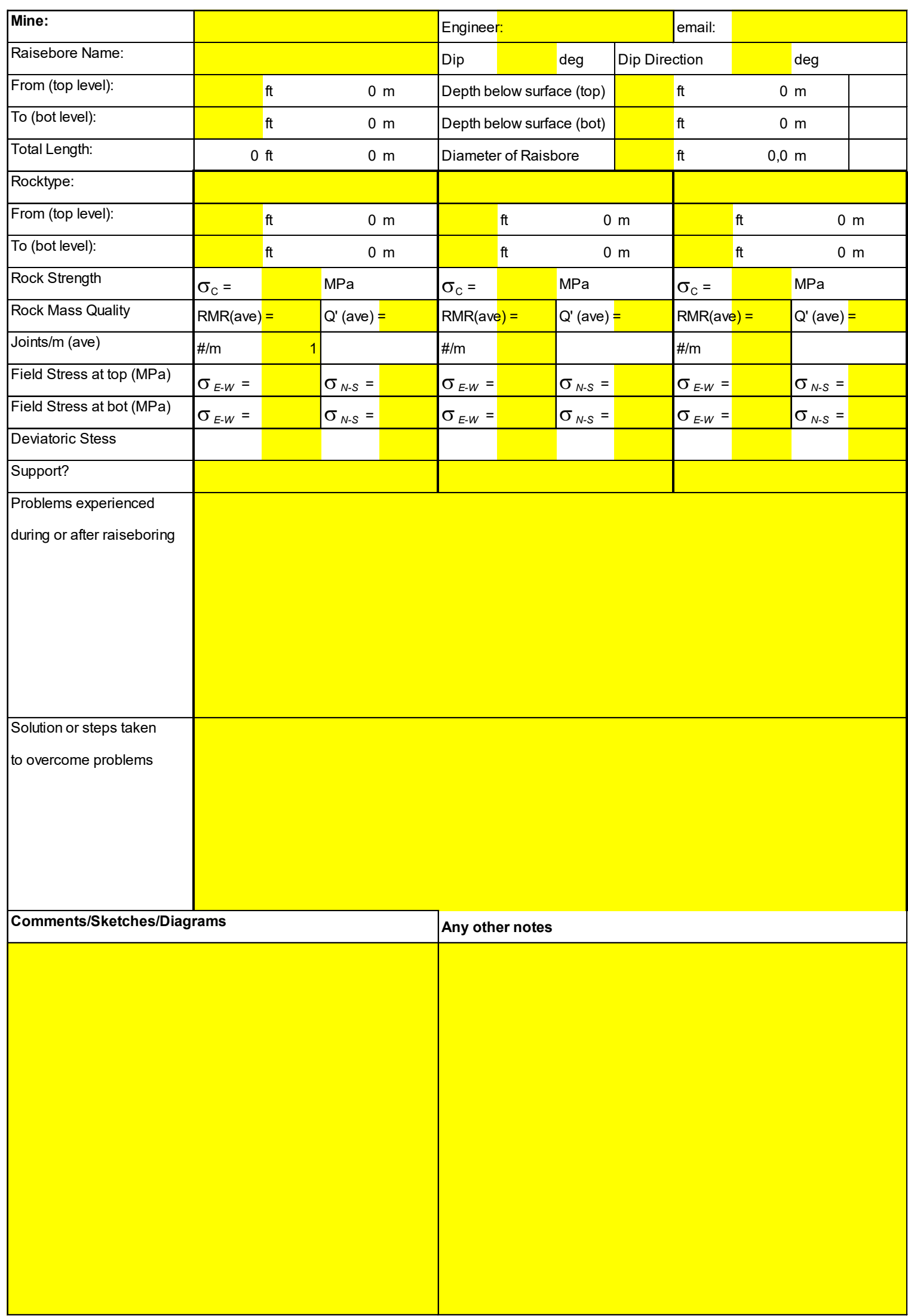

Figure 2 Raisebore data sheet. Items in yellow were completed by clients 


\section{Case studies of raisebored shafts}

Based on the available collected information, a selection of well-described cases (vertical shafts) are presented in this chapter. A summary of studied cases, which have had problems during raising and before commission, is presented in Table 1.

\subsection{Mine $\mathrm{A}-$ ventilation raise}

At Mine $A$ a $750 \mathrm{~m}$ long ventilation raise with bottom at 1,300 $\mathrm{m}$ depth was raisebored in heavily veined Quartz Monzodiorite. The diameter of the raise was $3 \mathrm{~m}$. The reaming stopped after $35 \mathrm{~m}$ due to poor ground conditions. Subsequent mucking produced significantly more tonnes than expected. A remote loader was used to clear the raise several times, however the raise would fail again within hours. After a short period of stability, the raise was fully mucked and the reamer head removed, with 10 cutters found to be missing, see Figure 3. The raise failed again after removal of the reamer and was left choked to help with rehab grouting. Probe drilling was carried out to determine the shape of the overbreak. These holes were then used to grout a 3-4 $\mathrm{m}$ high plug in the raise base. The remaining grout placement was done from the collar with lean mix in an attempt to fill void. The pilot hole was re-drilled once grouting was completed, and $2.4 \mathrm{~m}$ (as opposed to $3 \mathrm{~m}$ ) diameter reaming recommenced. The overbreak was attributed to locally low rock block strength from intense veining/microdefecting relative to high in situ horizontal stress.

In terms of characterisation, the main learning from the experience was to better account for the influence of veins and microdefects on the rock block strength when estimating raise stability. In terms of placement, the main learning was to use shorter raises to lower the risk. Moreover, the raises should be repositioned if core from the characterisation hole suggests weak ground that may lead to raise instability at a specific locale (e.g. move bottom up if needed and bore separate leg below).

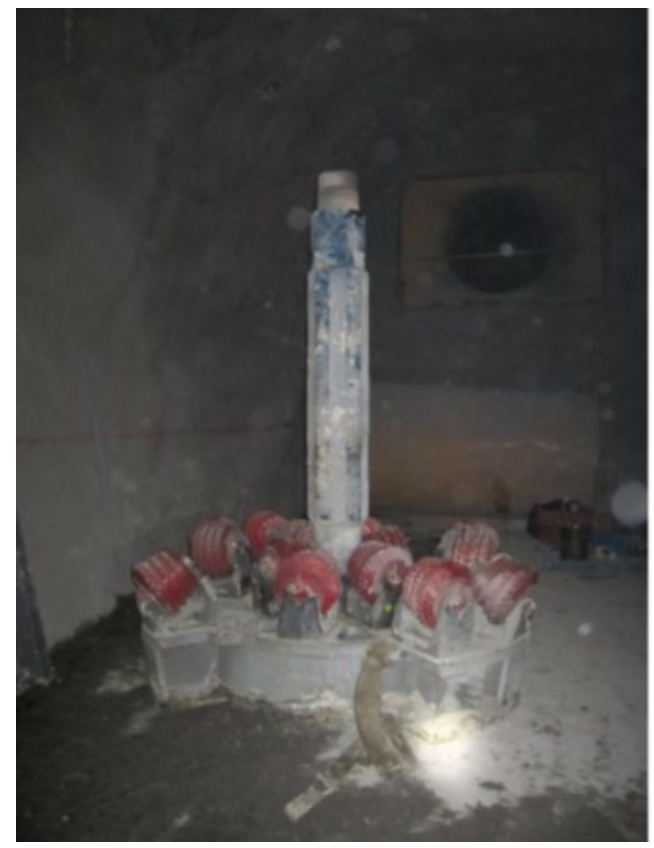

(a)

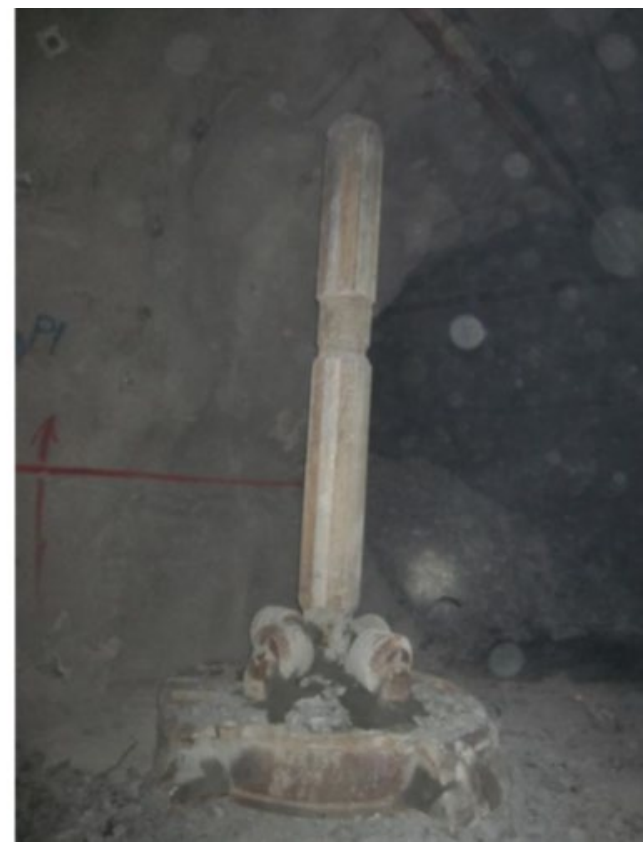

(b)

Figure 3 Reamer head before (a) and after (b) $35 \mathrm{~m}$ reaming 


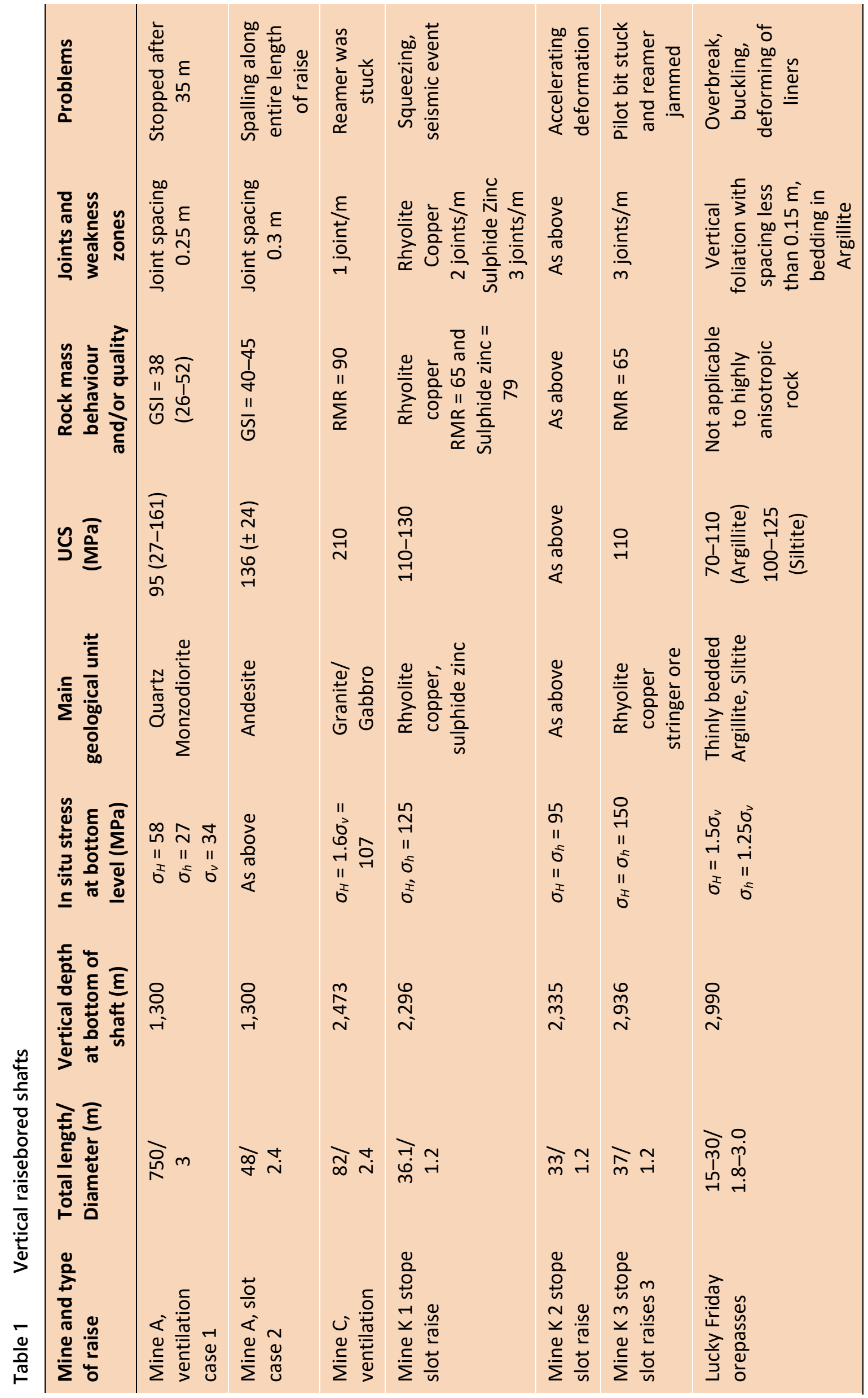




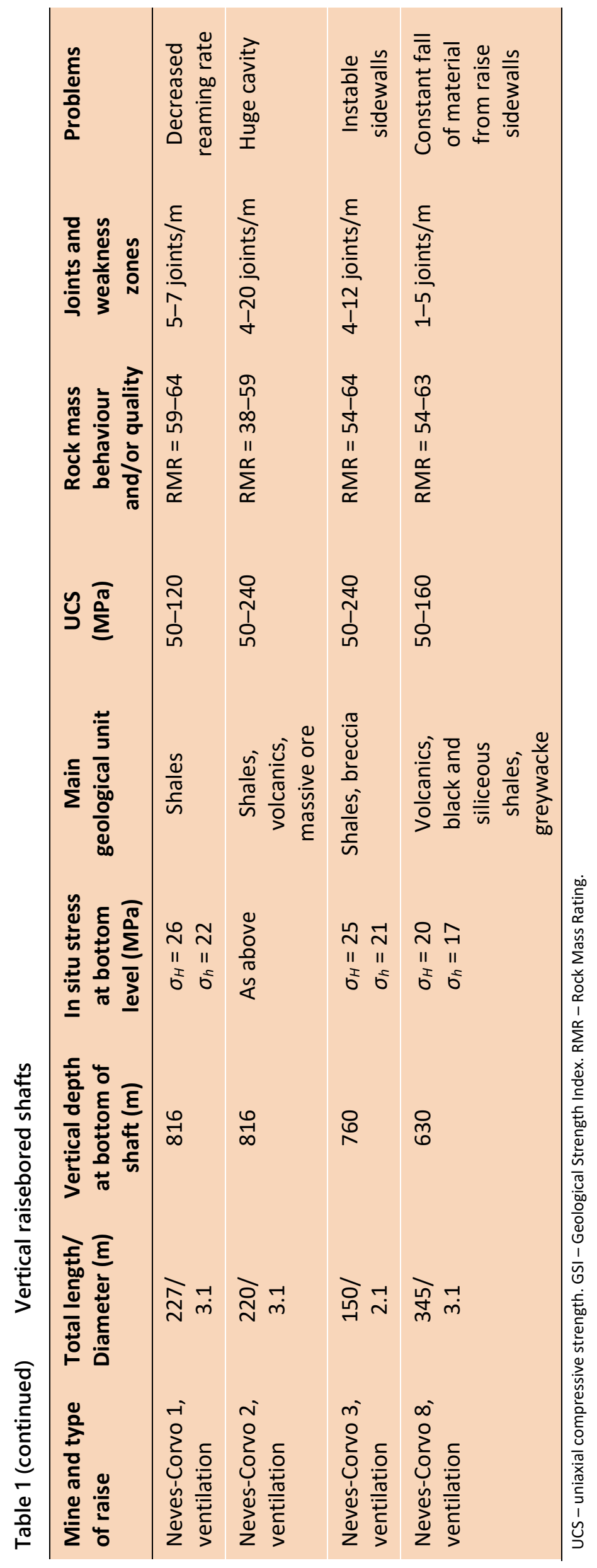




\subsection{Mine $\mathrm{C}-$ Ventilation raise}

Many shafts have been raisebored in Mine $C$ and this example is illustrative of the sort of problems experienced. An approximately $80 \mathrm{~m}$ fresh air raise (ventilation) was bored between depths of $2,473 \mathrm{~m}$ and $2,390 \mathrm{~m}$ below collar in a granite/gabbro with a uniaxial compressive strength (UCS) of about $210 \mathrm{MPa}$. The raise location was selected to avoid known geological units comprising shear zones, jointing, and ductile biotite.

No problems were experienced during pilot hole drilling, and reaming went relatively well, with only minor seismicity recorded, until approaching breakthrough. The plan was to pull the reamer through rather than to lower it in order to avoid blasting the breakthrough. The day shift raise crew stopped near breakthrough with no shift coming on in the afternoon. The next day the reamer was stuck. A plan of action was put together to release the reamer by blasting. After a couple of unsuccessful smaller blasts, it was decided to remove the raisebore off the platform before continuing. To do so, the pilot stem needed to be removed. Extra hitches were installed to hold the remaining stem as to not drop the reamer after release. This all resulted in project delays and a lot of additional work, as well as risk to equipment. The solution to overcome the issue is to 'hot-seat' the raise and have a continuous reaming ongoing upon approach to a breakthrough.

\subsection{Mine $\mathrm{K}$ - stope slot raises}

Mine $\mathrm{K}$ is a very deep blasthole mine that raisebores the slots for their blasthole stopes. Because of the sequence used, it is unavoidable that raisebores need to be developed in highly stressed ground. As an example, a raise was developed in a location where the major principal stress was roughly $150 \mathrm{MPa}$ in a rhyolite copper ore with UCS of about $110 \mathrm{MPa}$. Clearly this ground was highly overstressed before pilot drilling began.

The raise pilot hole began to squeeze on the rods during downdrilling. Operators had to trip rods multiple times to maintain pilot hole diameter, prior to attaching the reamer. During reaming, due to anticipated high rates of closure, the reamer was lowered out of the raise between afternoon and day shifts, and then 'reamed' back up to the 'face' to ensure the reamer would not be stuck in the raise. Multiple surveys were done in the raise, which showed large pockets of caving approximately 2 to $3 \mathrm{~m}$ below the overcut elevation. The orientation of where crushing occurred (Figure 4) was mapped to estimate the stress field orientation for future model updates during mining. Multiple seismic events with local magnitudes up to 2.8 during mining of the stope resulted in badly damaged rock mass around the raise, complicating drilling and mining processes.

\subsection{Lucky Friday mine - orepasses and ventilation raises}

At the Lucky Friday Mine raise lengths vary but orepasses are typically limited to $30 \mathrm{~m}$ length and vent raises limited to $15 \mathrm{~m}$ length. These are relatively deep raises, with most production currently conducted at 2,100 to 2,290 $\mathrm{m}$ depth (shaft bottom is at 2,990 $\mathrm{m}$ depth). The host rock is primarily a thinly-bedded argillite (UCS 70-110 MPa) which can, depending on the sand content, be siltite (100-125 MPa). The primary fractures in the rock are vertically-oriented foliation and bedding in the argillite. The spacing of the foliation varies, but is typically less than about $15 \mathrm{~cm}$. There is some widely-spaced horizontal jointing, but the vertical foliation dominates the rock mass response. Water seepage is minimal. The major principal in situ stress is horizontal, equal to 1.5 times the vertical stress and trends $\mathrm{N} 40 \mathrm{~W}$. The intermediate principal stress is horizontal as well and is 1.25 times the vertical stress.

Raises sometimes experience overbreak during reaming. Significant excavation interaction can occur when the vent raises are driven too close to the downward-direction, adjacent vein mining. Sometimes operators have to drop the reamer several times to keep the raise going. Instability typically includes buckling of the thin foliation into the raise and deforming of liners. The remedial measures on how to maintain wall stability for the Lucky Friday mine are presented in Section 5. 

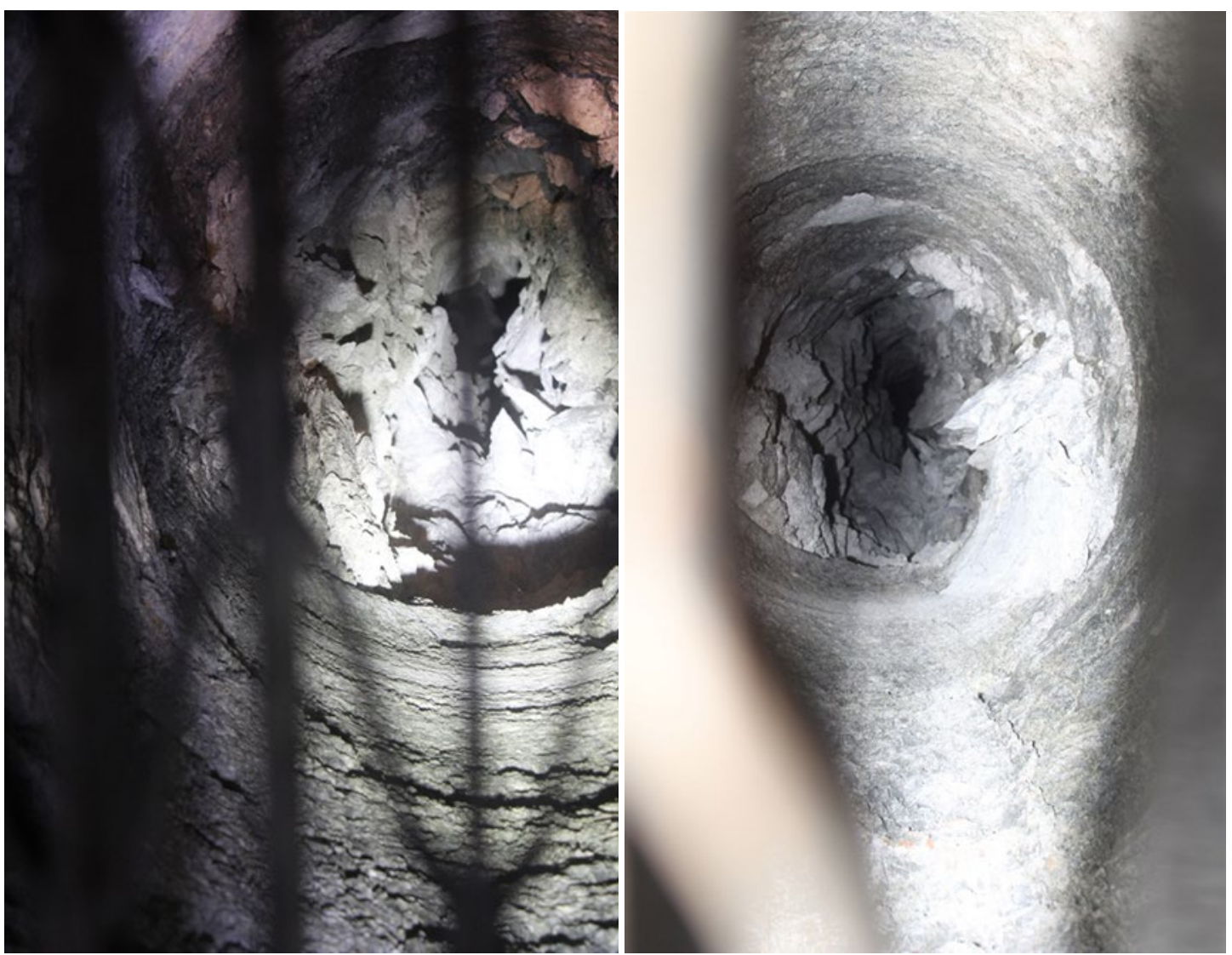

Figure 4 Views down slot raise soon after completion, showing severe crushing and squeezing close of raisebore

\subsection{Neves-Corvo Mine - ventilation raise}

Based on a comprehensive stability study work for shafts, orepasses and ventilation raises, data for a total of 11 ventilation raises and two orepasses was summarised by Somincor for this work. The diameters of the raises were $2.1,3.1$, and $4.1 \mathrm{~m}$ and with lengths of 66-345 m. Unstable sidewalls (some loose blocks or instability during the initial part of the excavation) were observed for six of the raises during reaming. In general, no support was installed in the raises, with the exception of lining used in weaker rock sections. No severe problems during reaming occurred for the raises in Neves-Corvo Mine. However, there were some issues regarding spalling, falling of material etc.

As an example, issues during reaming and developed cavities (based on filming the raise) were observed for a $220 \mathrm{~m}$ long ventilation raise (presented as Neves-Corvo 2 in Table 1) with a diameter of $3.1 \mathrm{~m}$. The rock types in the area were siliceous shales, volcanics, greywacke and massive ore. The UCS varied from 50 to $240 \mathrm{MPa}$ and the Rock Mass Rating (RMR) varied between 38 and 59. Shotcrete lining was performed for the first $56 \mathrm{~m}$. After $56 \mathrm{~m}$ it was not possible to shotcrete due to a huge cavity which the lining equipment could not cross. Hence, constant monitoring of the raise stability was performed. However, after the lining application the raise was stable.

\section{Design approach}

The empirical McCracken and Stacey method (McCracken \& Stacey 1989) is commonly used for first-pass designs of shafts. Design of, and methods for determining the life of, orepasses was reviewed and compiled by Brummer (1998). The McCracken and Stacey method addresses the initial stability of a shaft, but this method requires detailed geomechanics data that for many case studies is not available (Brummer 1998). In Brummer (1998) a survey of primarily Canadian industry mines in brittle, strong rocks was performed and a 
stability index was developed relating the laboratory intact UCS to the maximum tangential $\left(\sigma_{\max }=3 \sigma_{H}-\sigma_{h}\right)$ stress around circular orepasses.

The data obtained from the previous study (long-term stability) by Brummer (1998) together with data from the current study (short-term stability) allowed the further development of a Raisebore Design Chart relating the maximum tangential stress $\left(\sigma_{\max }=3 \sigma_{H}-\sigma_{h}\right)$ to UCS. It was apparent that this ratio could be plotted against the size of the raisebore (Figure 5) as well as the length of the raisebore (Figure 6). This enabled establishing what appeared to be limits for what can be achieved using today's technology. One of the important limits is the stress ratio at which the perimeter of the raise or pilot starts to fail because of the induced tangential stress around the raisebore. Based on failure observations this occurs at a $\sigma_{\max } / U C S$ ratio of about 0.3 , see Figure 5. The next limit, when severe spalling and crushing occurs, is at a $\sigma_{\max } / U C S$ ratio of about 1.2-1.5, based on industry experience. It can be further noted that for low $\sigma_{\max } /$ UCS ratios, in particular for the chart in Figure 6, the length of the shaft has less influence on the results. This is neither unreasonable, nor unexpected; however, for high ratios, the opposite is true, and both length and diameter are strongly restricted by the stress-strength conditions.

All cases presented in Table 1 are plotted in the charts together with cases which had no problems during raising. The problem-free raises are marked with green triangles and the cases with severe problems are marked with red squares. These charts can be applied to all type of raises as they consider the short-term condition. Like other empirical geomechanical design techniques these charts are intended to provide an indication of the potential for problem-free raising.

\section{Raisebore Design Chart}

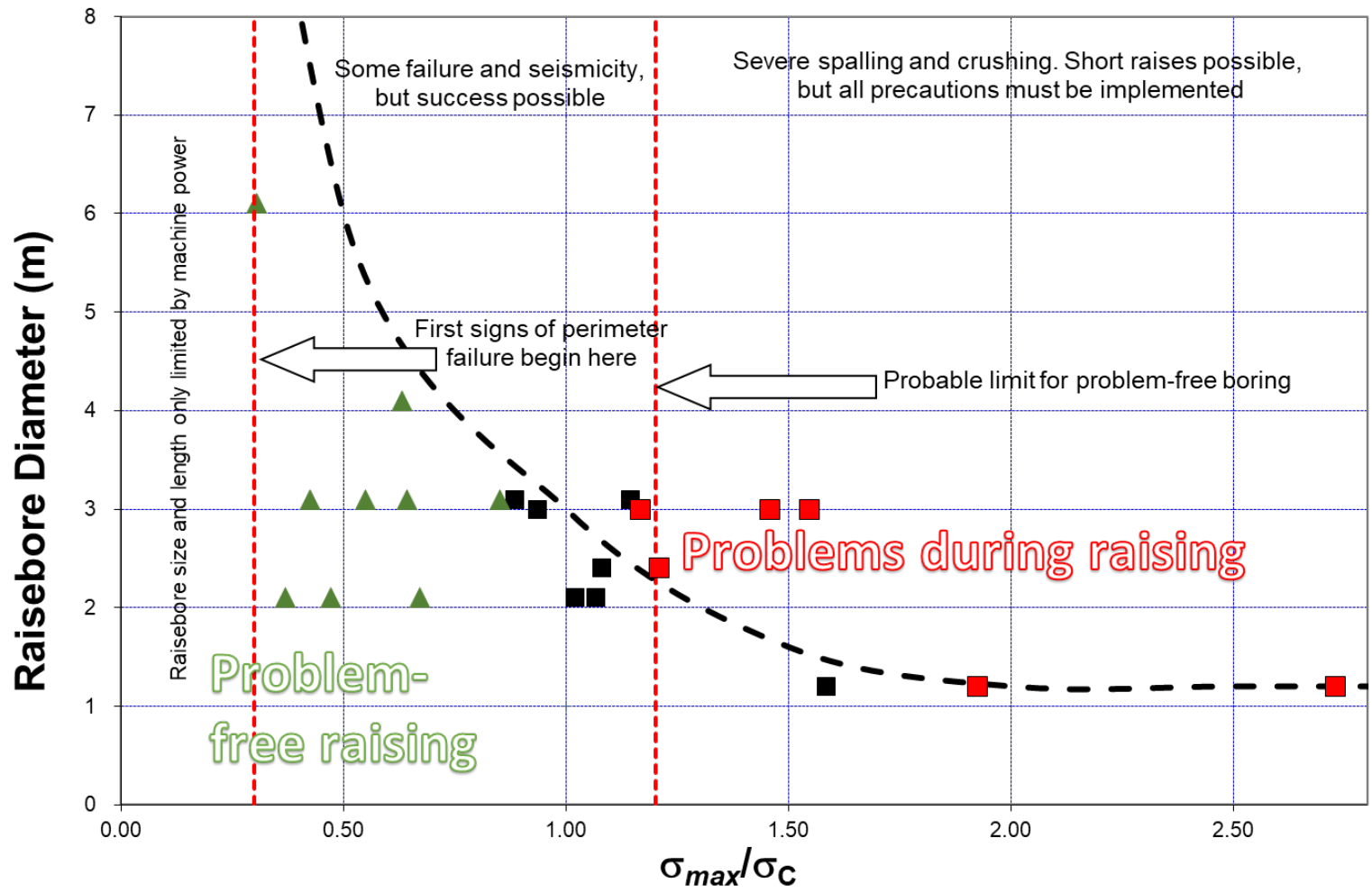

Figure 5 Raisebore design chart relating $\sigma_{\max } / \mathrm{UCS}$ ratio to raisebore diameter. Red squares represent severe problems, green triangles no problems and black squares some problems. The black dashed curve defines the approximate limit for problem-free raising 


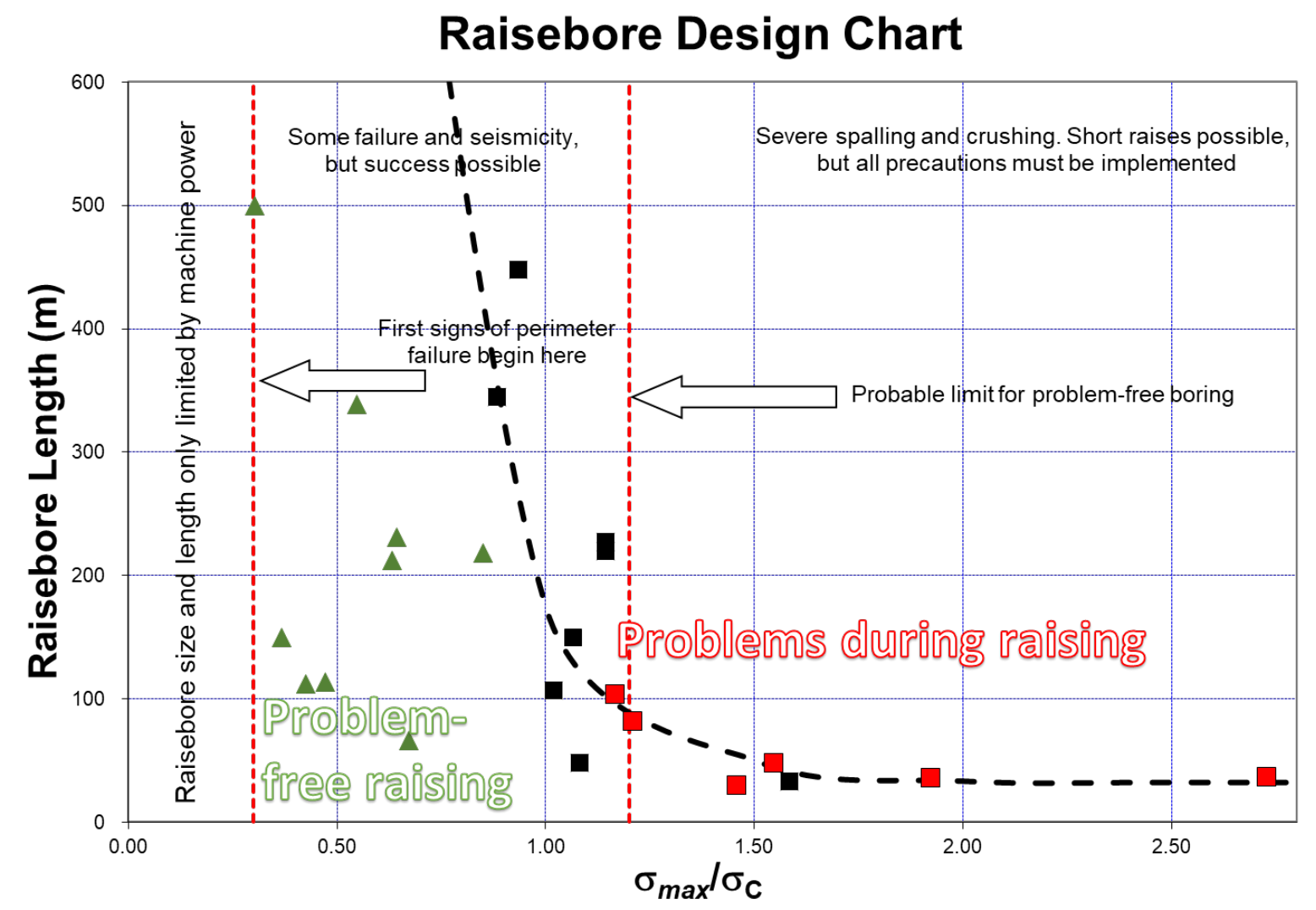

Figure 6 Raisebore design chart relating $\sigma_{\max } /$ UCS ratio to raisebore length. Red squares represent severe problems, green triangles no problems and black squares some problems. The black dashed curve defines the approximate limit for problem-free raising

\section{$5 \quad$ Remedial measures and ideas for the future}

The motivation for mining engineers is to improve the ground condition so that raises can be back-reamed full face and personnel do not have to work in shafts. Three different ways to support the walls or use prereinforcement are:

1. Lining the raise while pulling out the muck helps suppress failure as evidenced at the Lucky Friday Mine (see Section 3.4). If the hole behind the reamer is filled with muck, which supports the walls temporarily, a plastic pipe or steel conduit can float down from the top as the muck is pulled out. When complete, the annulus is backfilled with grout.

2. As presented in Vervoorn (2005), ground freezing has been used, for example, by the mining companies North Selby Coalfield (Yorkshire in UK), White County Coal (Illinois in USA), and Potash Mining (Saskatchewan in Canada). The purpose with freezing as a remedial measure is to increase the strength of a broken and fractured rock mass.

3. Pre-reinforcement by using rings of reinforced piles has been installed and trialled in mines such as the Bendigo Gold Mines, Callie Gold Mine, Cadia East, Mt Isa Mine, Olympic Dam, and Wattle Dam Gold mine (Marlow et al. 2013).

The most well documented cases on how to improve the shaft stability are from pre-reinforcement by using rings of reinforced piles. Therefore, this approach is further described for two cases. The first case is a $4.5 \mathrm{~m}$ diameter and $27 \mathrm{~m}$ long ventilation shaft which was raised in the Athena Gold Mine (Marlow et al. 2013). The site profile comprised an extremely weak upper zone (the top $10 \mathrm{~m}$ ) and a moderately weak lower zone (10-27 m depth). The stability of the raisebore shaft was assessed using two approaches: (i) the McCracken and Stacey method and (ii) the maximum stable unsupported span estimate. Results for both methods clearly showed that a conventional $4.5 \mathrm{~m}$ diameter raisebore would not be successful in this ground, with a 
probability of failure exceeding $50 \%$ over much of the length of the raise. A ring of 24 bored piles, nominally $27 \mathrm{~m}$ deep and with a pile diameter of $200 \mathrm{~mm}$, was installed around the shaft position. Since the pile length was close to the raise length, some piles were bedded into rock below the floor of the underground drive. Old drill rod reinforcement was grouted into the holes. The drill rods were linked and centralised in the holes by means of spacers at the collars. However, during reaming the reaming head hit some of the drill rods/piles, which required a change to a smaller reamer diameter.

Another example is the two $150 \mathrm{~m}$ deep ventilation shafts of 3 and $4 \mathrm{~m}$ diameter which were raisebored through to the surface in the Trident mine in 2007. Site investigation drilling confirmed about $50 \mathrm{~m}$ of weak weathered rock at both locations of the shafts, with sharp contacts to strong competent rocks. A 5 m thick zone of soft clay, located $25 \mathrm{~m}$ below surface, was found at the site with the $4 \mathrm{~m}$ diameter shaft. The excavation and reinforcement of the $4 \mathrm{~m}$ diameter shaft is presented in Sexton et al. (2008). A total of 20 non-contiguous, cable reinforced grouted minipiles were designed to be installed from surface down to fresh rock ( $55 \mathrm{~m}$ depth) before back-reaming. The layout was in the form of two rings of piles, the outer ring at $0.5 \mathrm{~m}$ standoff and with steel reinforcement, and the inner ring at $0.15 \mathrm{~m}$ standoff being grouted, see Figure 7. The piles were designed with $270 \mathrm{~mm}$ diameter and with a spacing less than $1.47 \mathrm{~m}$ (which required at least 11 piles in the outer ring and 10 piles in the inner ring).

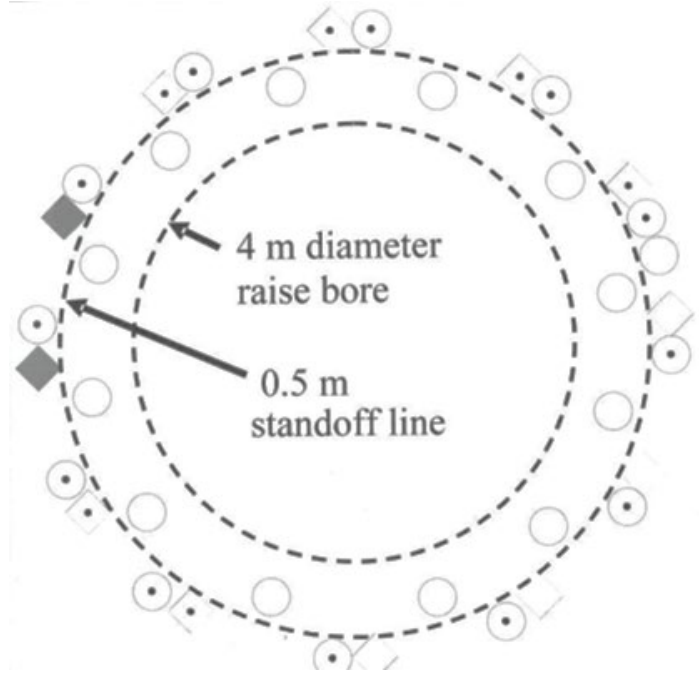

\author{
Cycle 1 Full depth andcabled \\ - Cycle 1 Partial depth and cabled \\ Cycle 1 Partial depth and notcabled \\ Cycle 2 Grouted only(grout curtain) \\ Cycle 2 Grouted and cabled
}

Figure 7 Layout of the vertical reinforced piles at the Trident Mine (Marlow et al. 2013)

Pile drilling problems was a major practical issue for the $4 \mathrm{~m}$ shaft in the Trident Mine. Only two holes were successful in the outer ring and the first cycle of holes, see cycle 1 in Figure 7. Hence, a second set of piles was designed, this time using $140 \mathrm{~mm}$ diameter reverse circulation (RC) drilling. A new inner ring was drilled and grouted in order to backfill the washouts from the original drilling in the outer ring. Subsequently, an outer ring of cable reinforced piles was constructed. The raise was then successfully reamed through to the surface. Some pieces of the inner piles were recovered from the cuttings. The excavated volume was $95 \mathrm{~m}^{3}$ more than expected over the full shaft length. This roughly equated to the observed overbreak of the raise walls, in one location extending out to the piles, which implied that the piles inhibited a larger collapse.

Factors to consider regarding pile planning and design (Marlow et al. 2013) are:

- Maximum allowable spacing or aperture between piles.

- Pile diameter.

- Standoff distance, which is the clear space between the bored edge of the raisebore and the edge of the piles.

- Expected verticality of the pile boreholes. 
There were no published case studies with pre-reinforcement in rock conditions with a combination of high stresses and weak and strong rock, similar to those of the Boliden mines. However, as vertical pre-reinforced holes have been trialled with success in many other mines, a ring along the whole length of the shaft is suggested as an idea for the future for the Boliden mines (Figure 8). The inner ring can be complemented with an outer ring (or several rings) with shorter holes, in the top and bottom of the shaft (Figure 9).

The holes could be reinforced using, for example, bolts (which are linked) or cable bolts and concrete (i.e. components with high tensile capacity as not to fail due to lateral movements). This set-up may work well also under high-stress conditions, but it may be questioned whether it could also sustain large strain bursts. For such conditions, additional studies, for example using numerical modelling, would be required.
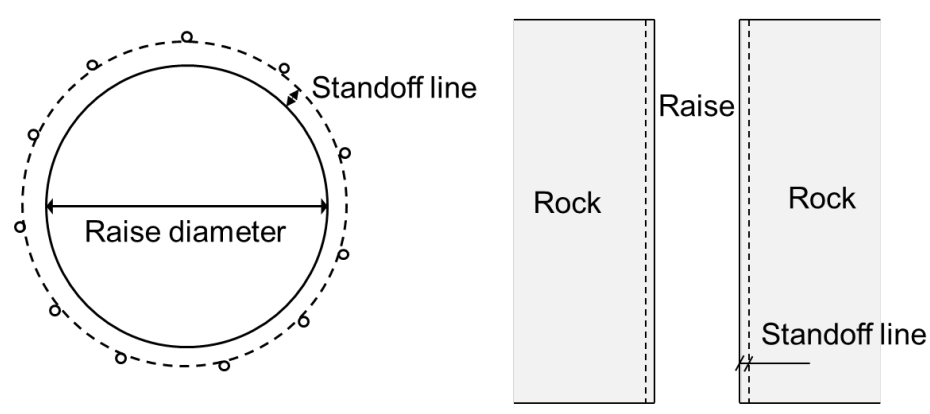

Figure 8 Example of layout of the vertical reinforced piles along the whole length of raise

\section{Horizontal view}

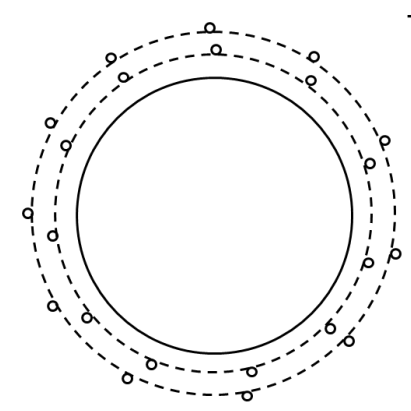

Vertical cross section

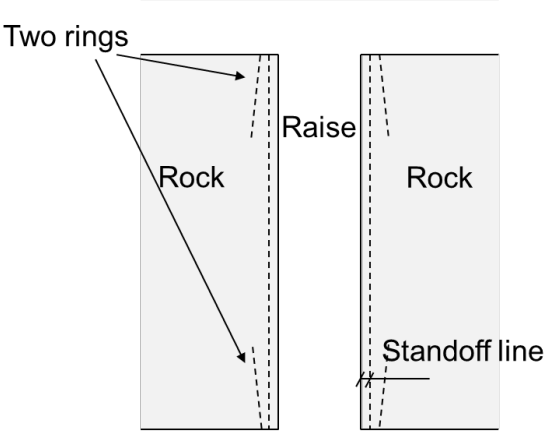

Figure 9 Example of layout using an inner and outer ring in the top and bottom of raise

\section{Concluding remarks}

Cases regarding raiseboring in difficult conditions have been summarised in this work. The raises vary in diameter $(1.2-6.1 \mathrm{~m})$ and length $(15-750 \mathrm{~m})$ and were developed in different ground conditions. Based on the information and experience reviewed during this study, the following strategies for raiseboring in difficult ground should be considered:

- Keep the reamer/cutter moving by 'hot change at the face' in order to avoid it to get stuck. This was the solution for the mine $C$ case in Section 3.2.

- If continuous drilling or reaming cannot be performed, then lower the head or pilot to the bottom and re-raise as for the mine $\mathrm{K}$ case in Section 3.3. 
- Reduce size of cutterhead if conditions become problematic and if a reduced diameter can be tolerated, as for the mine A case in Section 3.1.

- Use shorter raises to lower the risk and reposition raises if examination of rock cores from the characterisation holes suggests weak ground will lead to raise instability at a specific locale. This was concluded for the mine A case in Section 3.1.

The developed design charts can be used for any type of raise considering short-term stability. The charts can provide an indication of the likelihood of stress related problems during raising. For cases where severe spalling and crushing are likely to occur, further investigations regarding geology and rock mechanics are suggested. The main experience gained from the mine A case (Section 3.1), was to better account for the influence of veins and microdefects on the rock block strength when estimating raise stability. Hence, the focus should be on variation in rock strength, weakness zones, foliations, veins and microdefects, and also quantifying these.

Based on different methods to support the shaft walls, pre-reinforcement by using reinforced vertical holes is a suggested possible action. There is still uncertainty regarding for which conditions and for what potential failure mechanisms that this type of pre-reinforcement works. This should be further investigated, which may be done through numerical analysis.

\section{Acknowledgement}

We acknowledge all clients and mines who have shared information. A special thanks goes to João Gabriel (Mining Engineer at Somincor) who shared his experience and data from ventilation raises and orepasses in the Neves-Corvo mine.

\section{References}

Brummer, R 1998, Design of Orepasses: Methods for Determining the Useful Life of Orepasses Based on Previous Experience and Case Studies, submitted to CAMIRO Mining Division Limited, Sudbury, January 1998.

Marlow, P, Webber, S, Mikula, PA \& Lee, M 2013, 'Bored reinforced piles for raisebore support: four case studies, and guidelines developed from lessons learnt', Mining Technology, vol. 122, iss. 3, pp. 159-165.

McCracken, A \& Stacey, TR 1989, 'Geotechnical risk assessment for large-diameter raise-bored shafts', Proceedings of the Second International Conference on Shaft Design and Construction, Institute of Materials, Minerals and Mining, London.

Sexton, M, Mikula, PA \& Lee, MF 2008, 'Trident mine raise bore - a bored pile case study, Proceedings of the 1st Southern Hemisphere International Rock Mechanics Symposium, Australian Centre for Geomechanics, Perth, pp. 137-148.

Vervoorn, R 2005, Wall Support for Raise Bored Shafts, master thesis, Delft University of Technology, Delft. 
